\title{
Impact of Helicobacter pylori eradication on the gastric microbiome
}

\author{
Li-Qi Mao ${ }^{1,2+}$, Yan-Lin Zhou ${ }^{1 \dagger}$, Shuang-Shuang Wang ${ }^{1,3}$, Lin Chen ${ }^{1}$, Yue Hu ${ }^{1}$, Lei-Min Yu ${ }^{1,4}$, Jing-Ming Xu ${ }^{1}$ and \\ Bin $\operatorname{Lyu}^{1 *}$
}

\begin{abstract}
Background: Helicobacter pylori (Hp) eradication has been used for many years. Yet, the impact of this eradication on the normal gastric microflora is not well understood. In this study, we explored the effect of eradication on the stomach microbial community and its recovery after successful Hp eradication.
\end{abstract}

Methods: Among the 89 included patients, 23, 17, 40, and 9 were included in the Hp-negative, Hp-positive, successful eradication, and failed eradication groups, respectively. Four subgroups were further determined according to disease status (Hp-negative chronic gastritis [N-CG], Hp-negative atrophic gastritis [N-AG], successful-eradication chronic gastritis [SE-CG], and atrophic gastritis with successful eradication [SE-AG]). During the endoscopic examination, one piece of gastric mucosa tissue was obtained from the lesser curvature side of the gastric antrum and gastric corpus, respectively. In addition, $16 \mathrm{~S}$ rDNA gene sequencing was used to analyze the gastric mucosal microbiome.

Results: In the Hp-negative group, the gastric microbiota was dominated by five phyla: Firmicutes, Proteobacteria, Actinobacteria, Bacteroidetes, and Fusobacteria. After successfully eradicating $\mathrm{Hp}$, the bacterial flora in the stomach recovered to a considerable extent. In the failed eradication group, the flora was similar to the flora in Hp-positive subjects based on the alpha and beta diversities. Among the groups, Curvibacter and Acinetobacter were enriched in the presence of $\mathrm{Hp}$ (i.e., failed eradication and $\mathrm{Hp}$-positive groups), suggesting that these two genera could be used as biomarkers in the symbiotic flora in the presence of Hp. SE-CG was characterized by an increase in Firmicutes taxa and a decrease in Proteobacteria taxa compared with N-CG. SE-AG was characterized by a decrease in Firmicutes relative to $\mathrm{N}$-AG. Finally, no differences were found in the pairwise comparisons of nitrate and nitrite reductase functions of the microflora among the four subgroups.

Conclusions: After $\mathrm{Hp}$ infection, the diversity and relative abundance of gastric microflora were significantly decreased. Yet, gastric microbiota could be partially restored to the Hp-negative status after eradication. Still, this effect was incomplete and might contribute to the long-term risks.

Keywords: $16 \mathrm{~S}$ rDNA gene sequencing, Helicobacter pylori, Eradication therapy, Gastric microflora, Atrophic gastritis

*Correspondence: Ivbin@medmail.com.cn

†Li-Qi Mao and Yan-Lin Zhou have contributed equally to this work and share first authorship

${ }^{1}$ Department of Gastroenterology, The First Affiliated Hospital of Zhejiang Chinese Medical University, Hangzhou, China

Full list of author information is available at the end of the article

\begin{abstract}
Introduction
The gastrointestinal microbiome plays an important role in digestion, absorption, metabolism, immunity, and inhibition of pathogen colonization [1,2]. The imbalance of its structure or function can lead to many diseases [1, 2].
\end{abstract}

Helicobacter pylori $(\mathrm{Hp})$ is the most important and most studied bacterium of the stomach [3, 4]. Hp is a spiral-shaped Gram-negative bacterium transmitted original author(s) and the source, provide a link to the Creative Commons licence, and indicate if changes were made. The images or other third party material in this article are included in the article's Creative Commons licence, unless indicated otherwise in a credit line to the material. If material is not included in the article's Creative Commons licence and your intended use is not permitted by statutory regulation or exceeds the permitted use, you will need to obtain permission directly from the copyright holder. To view a copy of this licence, visit http://creativecommons.org/licenses/by/4.0/. The Creative Commons Public Domain Dedication waiver (http://creativeco mmons.org/publicdomain/zero/1.0/) applies to the data made available in this article, unless otherwise stated in a credit line to the data. 
through the fecal-oral route present in the gastrointestinal tract of more than half of people worldwide [5-7]. The worldwide prevalence of $\mathrm{Hp}$ infection is 44-49\%; more specifically, it is $26-37 \%$ in North America, $35-47 \%$ in Europe, $45 \%$ in Asia, $57-79 \%$ in Africa, $60-63 \%$ in Latin America, and $24-48 \%$ in Oceania [8, 9]. In China, the prevalence of $\mathrm{Hp}$ infection is $52-62 \%$ $[10,11]$. It is associated with various gastrointestinal diseases such as chronic gastritis, peptic ulcer, gastric mucosa-associated lymphoid tissue lymphoma, and gastric cancer $[5-7,12,13]$. Most patients acquire the infection during childhood [5-7]. Men appear to have slightly higher infection rates than women in adulthood, while in childhood sex ratio appears about even [5]. The risk factors include being socially disadvantaged, having a high number of siblings, and residing in or near endemic areas [5]. Adults and children infected with Hp can be asymptomatic or present with symptoms such as dyspepsia, epigastric abdominal pain, or signs of gastrointestinal bleeding. Smoking and chronic nonsteroidal anti-inflammatory drug (NSAID) use significantly increase the risk of peptic ulcer disease in those infected with $\mathrm{Hp}$. Hp eradication reduces the incidence of gastric cancer, and this benefit becomes more pronounced with increasing age [14-16]. Currently, eradication aims to prevent the development of stomach cancer $[17,18]$.

The core of Hp eradication treatment is the acid-suppressive effect of proton pump inhibitors (PPIs) and the bactericidal effect of antibiotics $[3,4,12,14,19-22]$, but antibiotic resistance is a growing concern $[5,6]$. PPIs increase the gastric $\mathrm{pH}$, while $\mathrm{Hp}$ prefers an acidic growth medium, and antibiotics exert a direct bactericidal effect [3, 4, 12, 14, 19-22]. The usual eradication regimens include bismuth quadruple therapy (PPI, bismuth subcitrate, metronidazole, and tetracycline; $10-14$ days), concomitant therapy (PPI, clarithromycin, amoxicillin, and nitroimidazole; $10-14$ days), and triple therapy (PPI, clarithromycin, and amoxicillin or metronidazole; 14 days) [5, 6]. Antibiotics have a direct and strong effect on all bacteria in the stomach [23]. The strong acid inhibitory effect of PPIs can sharply increase the stomach's $\mathrm{pH}$ value, thereby reducing gastric acid's effect on removing transient bacteria, which is not conducive to digestion and leads to various changes in substrate levels $[24,25]$. Although the drugs themselves and Hp's elimination have a potential effect on the gastric flora [19, 26], still a recent study indicated that $\mathrm{Hp}$ eradication might have a minimal impact on the gut microbiota [27]. There is an inverse association between $\mathrm{Hp}$ and the diversity of gastric microbiota [28]. The eradication of $\mathrm{Hp}$ might increase the diversity of gastric microbiota [20]. The relative abundance of other bacteria in the stomach might be restored after eradication to levels similar to individuals without Hp infection [20].

Using next-generation sequencing, the main phyla detected in the stomach are Proteobacteria, Firmicutes, Bacteroidetes, Actinobacteria, and Fusobacteria [29, 30]. The most abundant phyla change after $\mathrm{Hp}$ infection in the stomach, and Proteobacteria, Firmicutes, and Actinobacteria are the most represented [31]. The gastric cancer INS-GAS mouse model showed that the non-Hp flora could promote tumors [32, 33]. In addition, microbial diversity changes with the health of the gastric mucosal epithelium [34, 35]. Niche-specific microbial networks reflect the disease-specific microbiome, and diseaseassociated bacteria can form a cooperative network, contributing to the disease [36, 37]. In addition, previous research has mainly focused on the gastric microbiome of patients with gastric cancer rather than precancerous lesions such as gastritis atrophy (AG) $[14,29,32,34,38$, 39].

This study was developed on the hypothesis that $\mathrm{Hp}$ leads to change in gastric microbiota, that $\mathrm{Hp}$ eradication might restore gastric microbiome, and that non-Hp species might be involved in gastric lesion. Therefore, in this study, we analyzed the influence of eradication treatment on gastric flora and evaluated patients' recovery with successful eradication under different mucosal states. The microbiome was determined based on 16S rDNA sequencing, a common approach for such analysis [35, 40]. The results could indicate whether the changes in the microbiome after eradication might be related to the change in gastric cancer risk and whether failed eradication changes the microbiome.

\section{Methods}

\section{Patients and samples}

Gastric biopsies $(n=152)$ from different anatomical sites were obtained from 89 patients at The First Affiliated Hospital of Zhejiang Chinese Medical University, Hangzhou, China. This study was approved by the ethics committee of The First Affiliated Hospital of Zhejiang Chinese Medical University. All participants provided written informed consent for participation in this study.

Patients who underwent upper gastrointestinal endoscopy and were tested for Hp were included in this study, either because of symptoms of Hp infection or non-specific gastric symptoms. In addition, in China, the patients can request a gastroscopy as part of their annual physical examination, or specific insurance plans include a gastroscopy, even in the absence of symptoms.

The exclusion criteria were (1) patients who took PPIs, H2 receptor antagonists or other antacids, probiotics, mucosal protective agents, or antibiotics in the recent 4 weeks (all these drugs have a direct effect 
on the gastric mucosa flora; PPIs, $\mathrm{H} 2$ receptor antagonists, and other antacids increase the gastric $\mathrm{pH}$; probiotics are bacteria and obviously have a direct effect on the flora; mucosal protectant works by changing the mucosa of bacterial colonization; antibiotics have a direct bactericidal effect), (2) history of gastric adenoma, gastric cancer, or mucosa-associated lymphoid tissue lymphoma (all showed changes in the physiological structure of the gastric mucosa), (3) patients who underwent gastrectomy (most patients who have undergone gastrectomy have a history of advanced gastric cancer, and the normal physiological structure of the stomach has been altered), or (4) patients who underwent $\mathrm{Hp}$ eradication and were again $\mathrm{Hp}$-positive.

Most patients underwent a ${ }^{13} \mathrm{C}$ - or ${ }^{14} \mathrm{C}$-urea breath test and then gastroscopy 1-7 days later. During the endoscopic examination, one piece of gastric mucosa tissue was obtained from the antrum's lesser curvature side and another piece from the lesser curvature side of the corpus. Each specimen was placed in a separate sterile, nonpyrogenic, and DNase/RNase-free cryopreservation tube made of polypropylene to withstand temperatures to $-196{ }^{\circ} \mathrm{C}$ (Corning Inc., Corning, NY, USA). Those specimens were kept at $-80{ }^{\circ} \mathrm{C}$. Another mucosal biopsy of the gastric antrum was used for histological biopsy to assess gastric mucosa and Hp infection status. The ${ }^{13} \mathrm{C}$-urea breath test was performed by swallowing $75 \mathrm{mg}$ of ${ }^{13} \mathrm{C}$-urea. Breath samples were collected just before and $30 \mathrm{~min}$ after ingestion. The ${ }^{13} \mathrm{C}$-urea breath test was considered positive when delta over baseline (DOB) was greater than $4.0 \%$. Histological examination was performed using formalin-fixed paraffin-embedded blocks prepared from gastric biopsies. Sections were prepared and stained with Giemsa. Each glass slide was examined by a pathologist for the presence/absence of $\mathrm{Hp}$. Hp was cultured from the gastric biopsies. Hp was isolated on agar (brain-heart infusion). The agar plates were incubated in a microaerobic environment (5\% oxygen and $5-10 \% \mathrm{CO}_{2}$ ) for 5 days at $37^{\circ} \mathrm{C}$.

Current $\mathrm{Hp}$ infection was defined as a positive result from one of the following three tests: $(1){ }^{13} \mathrm{C}$-urea breath test, (2) histological examination, and (3) Hp culture. Furthermore, according to previous studies of the gastric microbiome, samples with $<1 \%$ of $\mathrm{Hp}$ relative abundance were excluded from the analysis to obtain higher representativeness [36, 41]. For patients with a history of eradication, we selected those with a completion time of 1 year. We combined the past and current Hp infection status to confirm the eradication. Only those whose gastric mucosa status was judged by endoscopy, further confirmed by pathological biopsy results, were classified into subgroups.
As per routine practice at our center, all Hp-infected patients were given a 14-day bismuth quadruple therapy consisting of omeprazole $20 \mathrm{mg}$, bismuth pectin $200 \mathrm{mg}$, furazolidone $100 \mathrm{mg}$, and amoxicillin $1000 \mathrm{mg}$, all twice daily. The outcome of the eradication therapy (for the patients who received it) was performed 4 weeks after eradication completion and was based on a ${ }^{13} \mathrm{C}$-urea breath test, histological examination, and Hp culture; any positive result was considered failed eradication. First, the patients were grouped as (a) group $\mathrm{N}$ (Hp-negative), (b) group P (Hp-positive), (c) group SE (Hp-positive and successful eradication), and (d) group FE (Hp-positive and failed eradication). Then based on the disease status, groups $\mathrm{N}$ and SE were divided into four subgroups: Hpnegative chronic gastritis [N-CG], Hp-negative gastritis atrophy [N-AG], successful-eradication chronic gastritis [SE-CG], and successful-eradication gastritis atrophy [SE-AG]).

\section{Analysis and testing process Extraction of bacterial DNA}

DNA from the different samples was extracted using the E.Z.N.A. ${ }^{\circledR}$ Tissue DNA Kit (Omega, Inc., USA) according to the manufacturer's instructions, which includes a bead-beating step for Gram-positive bacteria. Polymerase chain reaction (PCR) was used to amplify the $16 \mathrm{~S}$ rDNA V3-V4 region, using the 341F 5'-CCTACGGGNGGC WGCAG-3' ${ }^{\prime}$ and 805R 5'-GACTACHVGGGTATCTA ATCC- $3^{\prime}$ primers. The $5^{\prime}$ ends of the primers were tagged with specific barcodes per sample and sequencing universal primers. The thermocycler settings were (1) $98^{\circ} \mathrm{C}$ for $30 \mathrm{~s}$, (2) 32 cycles of denaturation at $98{ }^{\circ} \mathrm{C}$ for $10 \mathrm{~s}$, annealing at $54{ }^{\circ} \mathrm{C}$ for $30 \mathrm{~s}$, and extension at $72{ }^{\circ} \mathrm{C}$ for $45 \mathrm{~s}$, and (3) final extension at $72{ }^{\circ} \mathrm{C}$ for $10 \mathrm{~min}$. PCR amplification was performed in a $25-\mu \mathrm{L}$ reaction mixture containing $2.5 \mu \mathrm{L}$ of each primer, $12.5 \mu \mathrm{L}$ PCR Premix, $25 \mathrm{ng}$ of template DNA, and PCR-grade water to adjust the volume. The PCR products were confirmed using $2 \%$ agarose gel electrophoresis followed by purification with AMPure XT beads (Beckman Coulter Genomics, Danvers, MA, USA) and quantified by Qubit (Invitrogen, USA). Next, the amplicon pools were prepared for sequencing, an Agilent 2100 Bioanalyzer (Agilent, USA), and the Library Quantification Kit for Illumina (Kapa Biosciences, Woburn, MA, USA) were used to assess the size and quantity of the amplicon library, respectively. The libraries were then sequenced on the NovaSeq PE250 platform.

\section{Data processing}

The samples were sequenced on an Illumina NovaSeq platform according to the manufacturer's recommendations, provided by LC-Bio Technology Co., Ltd. 
(Hangzhou, China). Using unique barcodes, paired-end reads were assigned to samples and truncated by cutting off the barcode and primer sequence. FLASH was used to merge the paired-end reads. Quality filtering on the raw reads was performed under specific filtering conditions to obtain high-quality clean tags according to the fqtrim (v0.94). In order to ensure the accuracy and reliability of the results of subsequent analysis, the raw data were preprocessed to obtain the valid data for subsequent analysis. The primer sequences were removed. Each pair of pairedend reads were spliced into a longer tag. Windowed quality scanning was performed on the sequencing reads. The default scanning window was $100 \mathrm{bp}$. When the average quality value in the window was $<20$, the part of the read from the beginning of the window to the end of 3 'was truncated. The truncated sequences with a length less than 100 bp were removed. The truncated sequences containing $\mathrm{N}$ (uncertain fuzzy base) $>5 \%$ were removed. The chimera sequences were removed. In this study, FLASH (Fast Length Adjustment of Short reads, V1.2.8, FLASH) was used to splice the double-ended sequences. Vsearch software (v2.3.4) was used to filter chimeric sequences. After dereplication using DADA2, the feature table and feature sequence were obtained. Next, we calculated alpha and beta diversities by random normalization to the same sequences. Feature abundance was normalized using the relative abundance of each sample, according to the SILVA (release 132) classifier. Alpha and beta diversities were calculated by QIIME2. Alpha diversity was determined by the observed species, Chaol, Shannon index, and Simpson index. Beta diversity was assessed by weighted UniFrac distance matrices and visualized by principal coordinate analysis ( $\mathrm{PCoA})$. A total of 62 pairs of samples (124 in total) were used to compare diversity. All diagrams were produced using the R package (v3.5.0). BLAST was used for sequence alignment, and the feature sequences were annotated with the SILVA database for each representative sequence.

\section{Detection of differential taxa and prediction of metagenomic functions}

A linear discriminant analysis (LDA) and effect size (LEfSe) were performed to determine the important bacterial taxa in the comparison group. The Phylogenetic Investigation of Communities by Reconstruction of Unobserved States 2 (PICRUSt2) program (https:// github.com/picrust/picrust2) was used to infer the metagenome functional content based on the microbial community profiles obtained from the $16 \mathrm{~S}$ rDNA gene sequences. Predicted functional genes were categorized using Kyoto Encyclopedia of Genes and Genome (KEGG) ontology (KO).

\section{Statistical analysis}

Quantitative variables were analyzed using the MannWhitney U-test for the comparison of two groups. The LEfSe analysis and the comparisons of more than two groups were performed using the Kruskal-Wallis test and Wilcoxon rank-sum test. Predicted KO functions were analyzed in STAMP using the two-group comparison with White's non-parametric t-test and corrected for multiple tests with Benjamini-Hochberg's false discovery rate. All P-values were bilateral; a P-value $<0.05$ was considered statistically significant.

\section{Results}

\section{Characteristics of the patients}

The characteristics of all patients are compiled in Table 1. Additional file 1: Table S1 presents the results of each patient.

\section{Gastric antrum versus corpus mucosa}

An average of 81,829 reads was obtained from each sample, and an average of 73,605 reads from each sample was entered into subsequent analysis after filtration. About $93.51 \%$ of the sequences were distributed on 400-500 nucleotides. An average of 8224 reads (10.05\%) was filtered. The examination results of each patient are listed in Additional file 1: Table S1. In order to evaluate the alterations in the microbiota structure between the gastric antrum and corpus, we measured the microbial alpha and beta diversities. Alpha diversity showed a high degree of similarity (Fig. 1A). Beta diversity revealed no significant differences between paired sample locations (ANOSIM $\mathrm{R}=-0.0131, \mathrm{P}=0.97$, Fig. 2A). In Fig. 2A, the lower left included the samples from the $\mathrm{P}$ and $\mathrm{FE}$ groups, and the upper right included the samples from the $\mathrm{N}$ and SE groups. In other words, the lower-left group was Hp-infected, and the upper right group was

Table 1 Characteristics of the patients

\begin{tabular}{lll}
\hline Characteristics & $\begin{array}{l}\text { Age } \\
\text { Years mean } \pm \text { SD }\end{array}$ & $\begin{array}{l}\text { Sex } \\
\text { Female/Male }\end{array}$ \\
\hline All patients $(n=89)$ & $52.7 \pm 14.1$ & $45 / 44$ \\
Negative $(n=23)$ & $53.5 \pm 13.4$ & $13 / 10$ \\
N-CG $(n=14)$ & $46.6 \pm 11.8$ & $8 / 6$ \\
N-AG $(n=6)$ & $64.7 \pm 8.8$ & $2 / 4$ \\
Positive $(n=17)$ & $41.2 \pm 12.6$ & $9 / 8$ \\
Successful $(n=40)$ & $58.2 \pm 10.9$ & $19 / 21$ \\
SE-CG $(n=8)$ & $49.3 \pm 9.9$ & $7 / 1$ \\
SE-AG $(n=29)$ & $62.1 \pm 8.5$ & $9 / 20$ \\
Failed $(n=9)$ & $48.1 \pm 17.8$ & $4 / 5$ \\
\hline
\end{tabular}

N-CG: Helicobacter pylori-negative, chronic gastritis; N-AG: Helicobacter pylorinegative, atrophic gastritis; SE-CG: successful eradication, chronic gastritis; N-AG: successful eradication, atrophic gastritis 

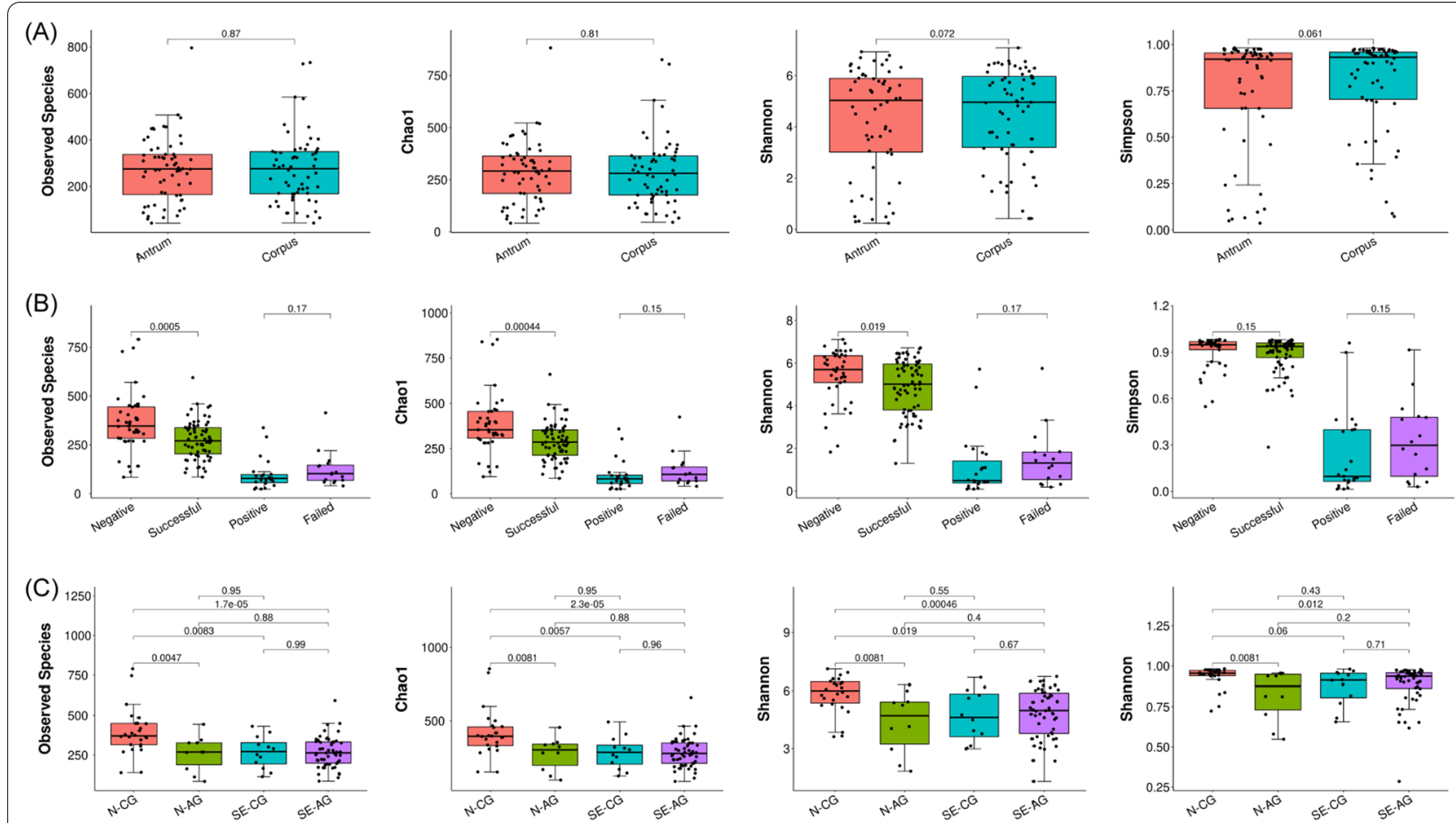

Fig. 1 The Alpha diversity was evaluated and transformed into a box plot. The species diversity and complexity of the samples were analyzed by four indices, including Observed species, Chaol, Shannon index, and Simpson index. A Boxplot in the gastric antrum and corpus mucosa groups. B Boxplot in the four groups: Hp-Negative, Hp-Positive, Successful Eradication, and Failed Eradication. C Boxplot in the four subgroups: N-CG, N-AG, SE-CG, and SE-AG. Statistical significance was determined by the Wilcoxon test

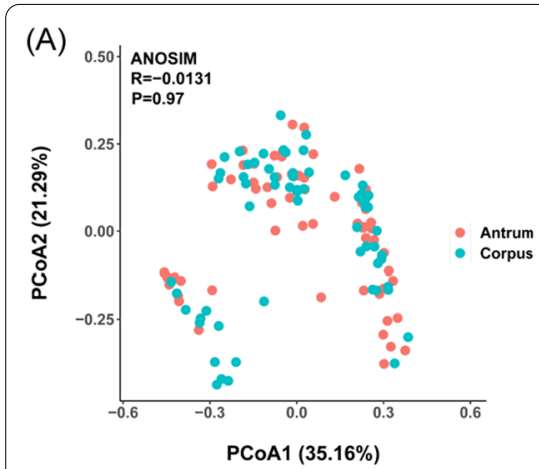

(D)

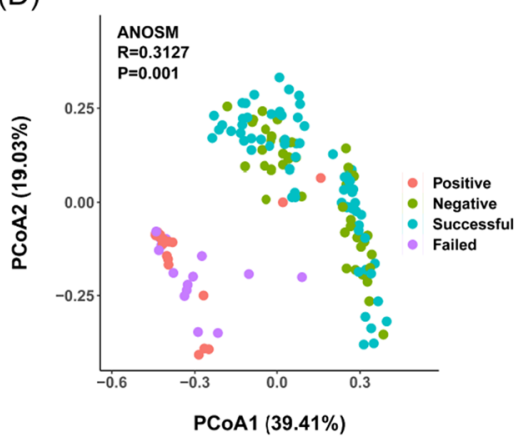

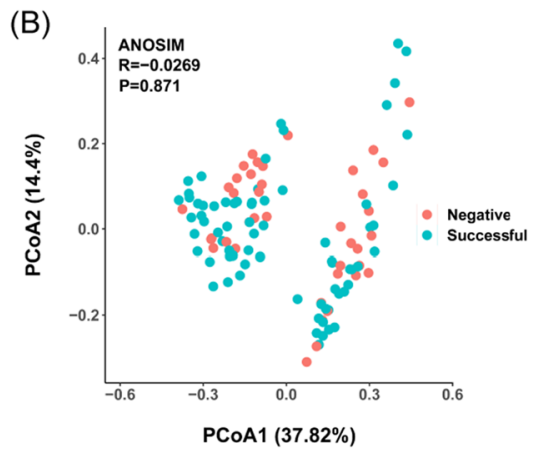

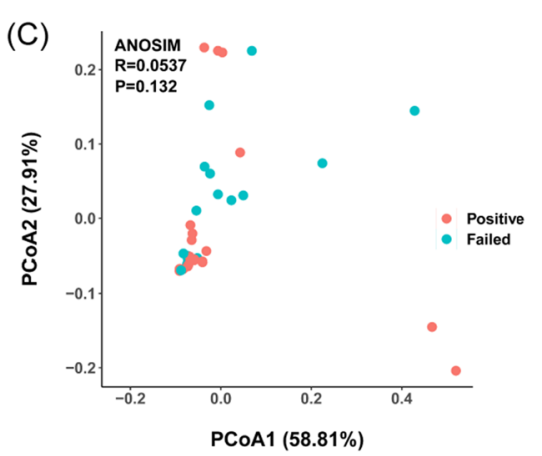

Fig. 2 Principal coordinate analysis (PCOA) plots in which the samples were colored based on $\mathbf{A}$ paired sample location and clinical grouping: B Hp-Negative vs. Successful-eradication; C Hp-Positive vs. Failed-eradication; D all four groups; E four subgroups. ANOSIM, analysis of similarity 
Hp-uninfected. Furthermore, the LEfSe analysis (LDA $>3.5$ ) revealed no positive results (observed species, $\mathrm{P}=$ 0.87; Chao1, $\mathrm{P}=0.81$; Shannon index, $\mathrm{P}=0.072$; Simpson index, $\mathrm{P}=0.061$ ).

\section{The effect of $\mathrm{Hp}$ on gastric flora}

In the Hp-negative group, the gastric microbiota was dominated by Firmicutes (32.95\%), Proteobacteria (32.26\%), Actinobacteria (11.80\%), Bacteroidetes (8.32\%), and Fusobacteria (3.03\%). At the same time, Epsilonbacteraeota (85.74\%), Proteobacteria (4.31\%), Firmicutes (3.21\%), Bacteroidetes (2.72\%), and Actinobacteria (1.49\%) were the top five phyla in the Hp-positive group. According to the new classification standard, the original Epsilonproteobacteria (class level) is now assigned to Epsilonbacteraeota (phylum level), so Helicobacter (genus level) no longer belongs to Proteobacteria (phylum level) $[42,43]$. Based on these changes, we described Epsilonbacteraeota as the dominant phylum and Helicobacter as the dominant genus (both over $80 \%$ ) in the P and FE samples (Fig. 4A). Relative abundance of different taxa was shown as histograms (Additional file 3: Figure S1).

In order to identify the potential biomarkers for $\mathrm{Hp}$ infection, we conducted a LEfSe analysis between the paired groups (groups $\mathrm{N}$ vs. P, groups $\mathrm{SE}$ vs. FE). A relative abundance cutoff was not set, as in the presence of $\mathrm{Hp}, \mathrm{Hp}$ relative abundance was often very high, and the relative abundance of all other flora was low. We selected the common bacteria at different levels through the Wilcoxon rank-sum test. In groups $\mathrm{P}$ and $\mathrm{FE}$, Campylobacteria, Campylobacterales, Helicobacteraceae, and Helicobacter were predominant in class, order, family, and genus levels, respectively (Fig. 3A). We performed a reanalysis by subtracting the Helicobacter readings from the data set to examine other taxa associated with the disease. Most genera observed a significant decrease even if the Helicobacter reads were removed from groups $\mathrm{P}$ and FE. In Fig. 3B, groups $P$ and FE were relatively enriched for the confirmed genera Curvibacter and Acinetobacter. All potential biomarkers are shown in Fig. $3 \mathrm{~A}$ and $\mathrm{B}$. The correlation between the two genera (biomarkers) with inferred functions in the $\mathrm{P}$ and $\mathrm{FE}$ groups is provided in Additional file 3: Figure S2.

\section{The gastric flora after $\mathrm{Hp}$ eradication}

First, we compared the gastric flora of the $\mathrm{N}$ and SE samples and the P and FE samples by analyzing the alpha and beta diversities. Despite the Simpson index having

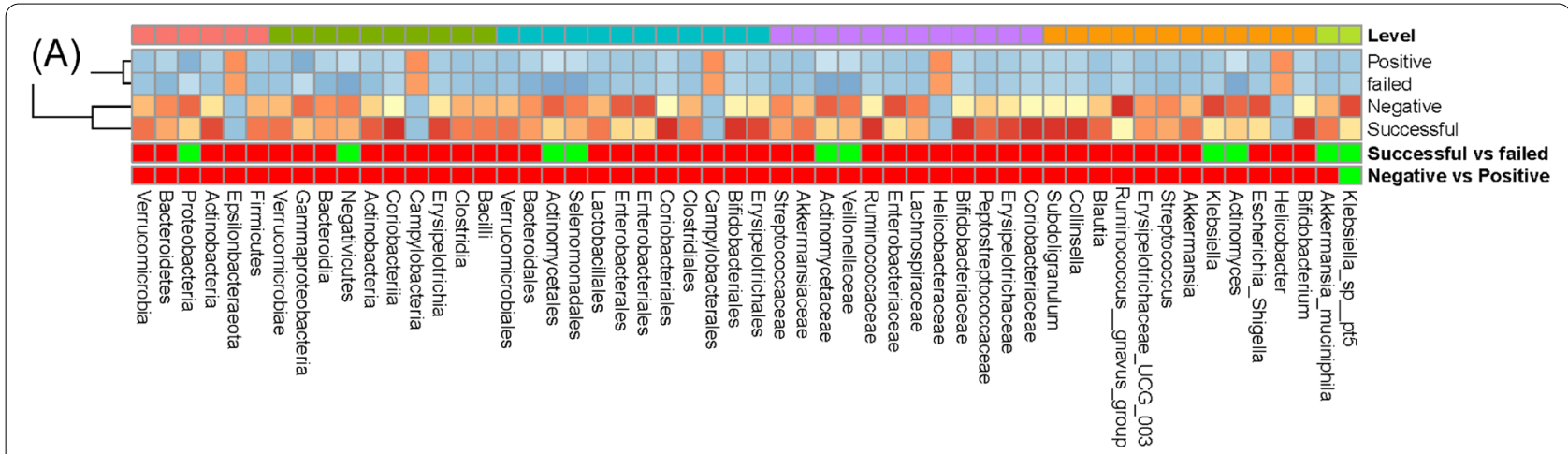

(B)
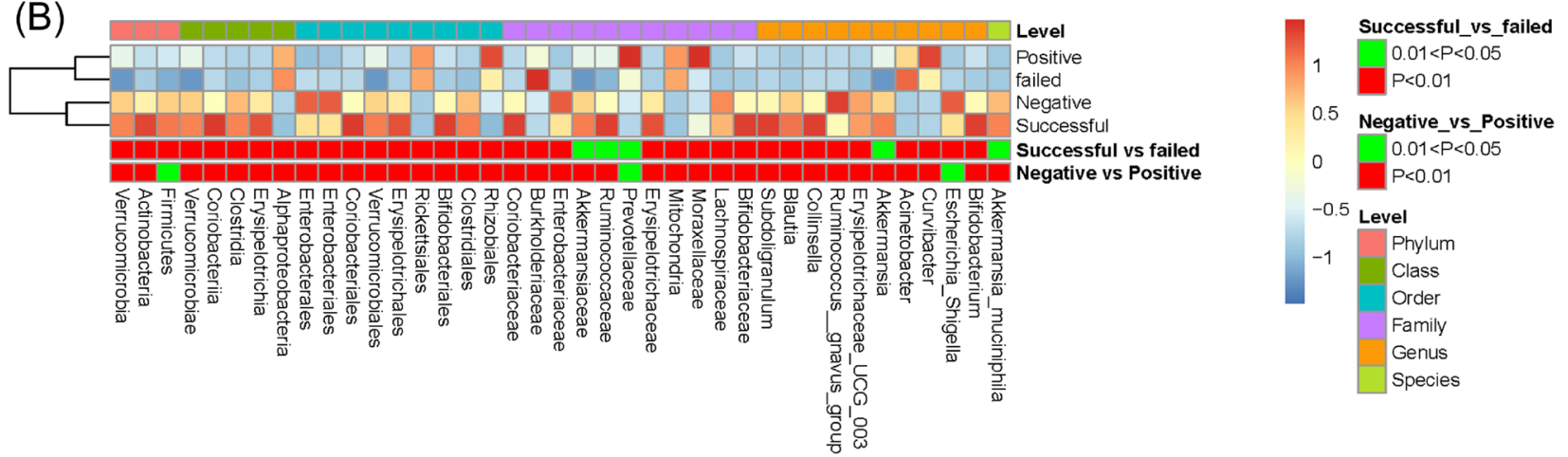

Fig. 3 The Z-score was obtained by subtracting the average abundance and dividing it by the standard deviation of all samples. By converting the $Z$ score into a heat map, the results of significant features (LDA score $>3.5$ and adjusted $\mathrm{P}<0.1$ ) were displayed, including $\mathrm{Hp}(\mathbf{A})$ and excluding $\mathrm{Hp}$ (B) related reads, $\mathrm{P}<0.01$ and $\mathrm{P}<0.05$ are marked in red and green, respectively 

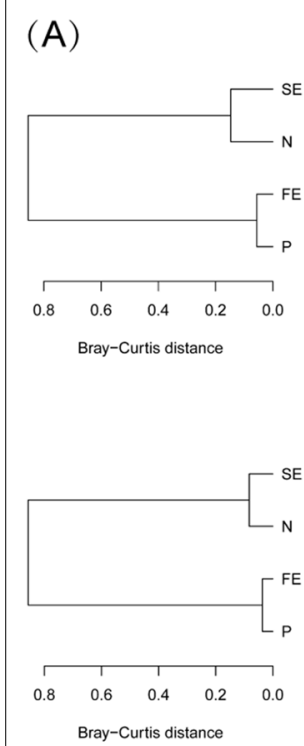
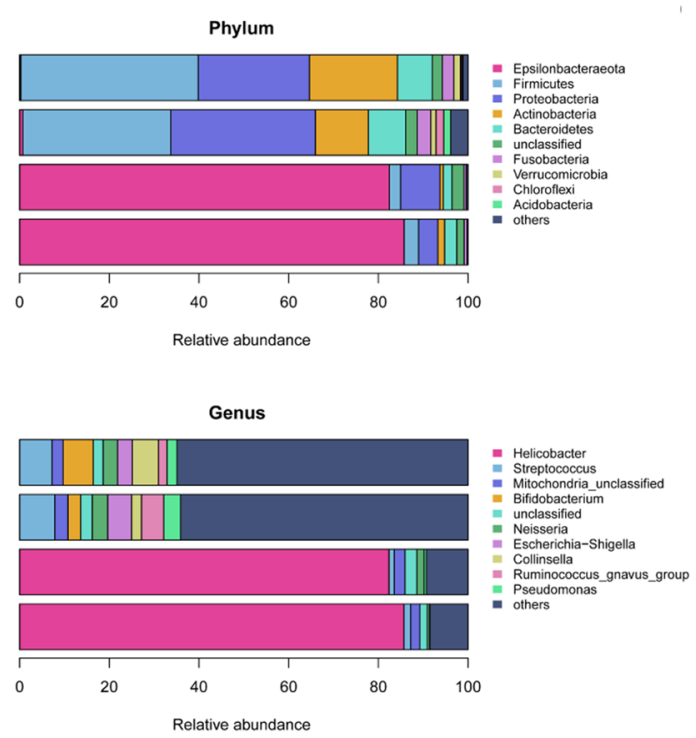

(B)

\begin{tabular}{lll}
\hline Group & Firmicutes / $P$ value & Proteobacteria $/ P$ value \\
\hline N_CG vs N_AG & 25.51 vs $60.55(<0.001)$ & 34.26 vs $19.87(0.087)$ \\
SE_CG vs SE_AG & 44.16 vs $39.64(0.528)$ & 20.39 vs $24.69(0.430)$ \\
N_CG vs SE_CG & 25.51 vs $44.16(0.009)$ & 34.26 vs $20.39(0.016)$ \\
N_AG vs SE_AG & 60.55 vs $39.64(0.015)$ & 19.87 vs $24.69(0.460)$ \\
N_CG vs SE_AG & 25.51 vs $39.64(0.029)$ & 34.26 vs $24.69(0.041)$ \\
N_AG vs SE_CG & 60.55 vs $44.16(0.107)$ & 19.87 vs $20.39(0.974)$ \\
\hline
\end{tabular}
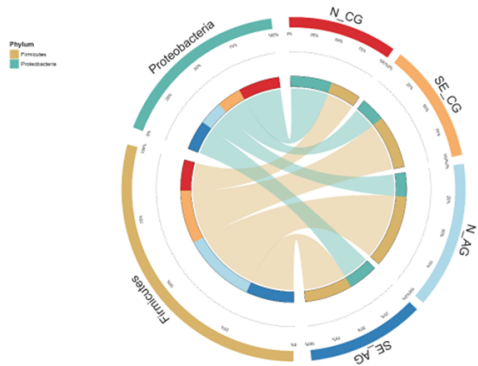

Fig. 4 A Top 10 relative abundance and Bray-Curtis distance of the four groups (P, N, SE, and FE) were displayed at the phylum and genus levels. Similar bacterial composition was observed between $\mathrm{N}$ and SE and between P and FE. Bray-Curtis distances were used to determine the similarity of groups based on bacteria composition. B The average relative abundance of the two main phyla under different references in groups $\mathrm{N}$ and $\mathrm{SE}$ and subgroups were compared, and the significance was calculated by the Mann-Whitney test $(P<0.05)$. The average relative abundance was also shown by the Circos plot

no significant differences in the $\mathrm{N}$ patients, significant reductions of the observed species, Chao1, and Shannon index were found in SE patients (Fig. 1B). No obvious differences were found between the $P$ and FE patients (Simpson index, $\mathrm{P}=0.15$; observed species, $\mathrm{P}=0.0005$; Chao1, $\mathrm{P}=0.00044)$. The beta diversity analysis revealed no remarkable differences in microbial diversity between the $\mathrm{N}$ and SE patients (ANOSIM $\mathrm{R}=-0.0269, \mathrm{P}=$ 0.871 , Fig. $2 \mathrm{~B}$ ), as well as between the $\mathrm{P}$ and $\mathrm{FE}$ patients (ANOSIM R $=0.0537, \mathrm{P}=0.132$, Fig. 2C) (observed species, $\mathrm{P}=0.17$; Chao1, $\mathrm{P}=0.15$; Shannon index, $\mathrm{P}=0.17$; Simpson index, $\mathrm{P}=0.15$ ). Figure $2 \mathrm{~B}$ contains all the samples in the $\mathrm{N}$ and SE groups. When reviewing the scatter distribution of each sample, it is found that the scatter distribution of each sample is random (not regular with the antrum, corpus and subgroup). Considering that the two groups are evenly distributed on both sides, this socalled clustering may not appear after the sample size is further increased. In Fig. $2 \mathrm{C}$, groups $\mathrm{P}$ and $\mathrm{FE}$ were not clustered well, mainly because of the small number of people in the two groups and also because the relative abundance of $\mathrm{Hp}$ varies among the samples (which was also magnified by the small number of samples). Because $\mathrm{Hp}$ relative abundance greater than $1 \%$ was considered to be $\mathrm{Hp}$ infection, although most of the samples in the $\mathrm{P}$ and FE groups were more than $80 \%$, there was some low $\mathrm{Hp}$ relative abundance, such as the four outliers on the right, which were all low Hp relative abundance (10.47\%,
$21.11 \%, 27.40 \%$, and $54.65 \%)$. This difference was not considered significant because the scattered points of the samples (antra and corpora) of the two groups were all reflected in the figure. Due to the high relative abundance of $\mathrm{Hp}$ in the matched samples, the degree of aggregation was relatively concentrated on the left side. Still, in Fig. 4D, when all the samples from the four groups were compared together, the P and FE groups appeared to be relatively well aggregated, as were the SE and $\mathrm{N}$ groups. When analyzing the four groups together, we distinguished two pairs of groups from sample distribution (ANOSIM R $=0.3127, \mathrm{P}=0.001$, Fig. 2D). As the dominant phyla, the sum of the relative abundance of Firmicutes and Proteobacteria exceeded 60\% in groups $\mathrm{N}$ and $\mathrm{SE}$, and the main genera were Streptococcus, Bifidobacterium, Escherichia-Shigella, Collinsella, Ruminococcus gnavus group, Neisseria, Pseudomonas, and unclassified Mitochondria (Fig. 4A). By comparing the bacterial composition among the four groups, the bacterial composition of groups $\mathrm{P}$ and FE were highly similar, as well as between groups $\mathrm{N}$ and $\mathrm{SE}$.

The LEfSe analysis was used to identify the potential differences in the abundance of the different bacterial taxa in groups $\mathrm{N}$ and SE. In the two groups, differences were found in 13 taxa (all had LDA scores $>3.5$ and $\mathrm{P}$ $<0.05$ ) (Fig. 5A). Relative to the $\mathrm{N}$ patients, SE patients exhibited preferential enrichment for Actinobacteria, whereas 12 bacterial taxa were preferentially depleted. 


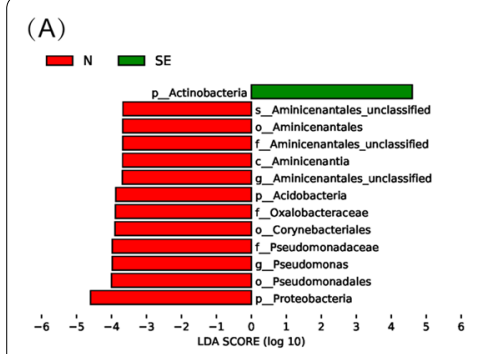

(B)

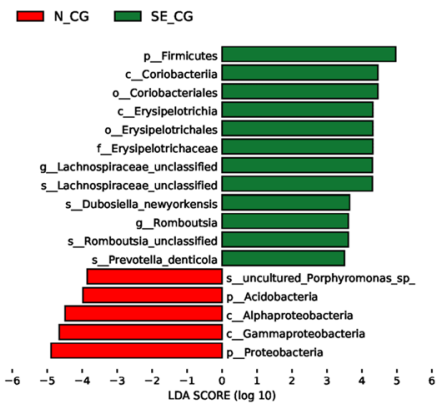

(C)

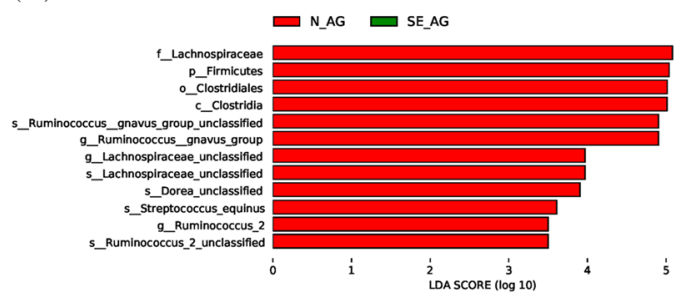

Fig. 5 Association of specific microbiota taxa with the group of chronic gastritis and gastric carcinoma by LEfSe (LDA score $>3.5, P<0.05)$. We presented the results of the analysis between N and SE (A), N-CG and SE-CG (B), and N-AG and SE-AG (C)

Specifically, the increased genera in group $\mathrm{N}$ included Pseudomonas and unclassified Aminicenantales. In group $\mathrm{FE}$, no taxa were distinguished from group P (Additional file 2: Table S2).

Both the SE and FE groups received eradication therapy, and the difference was whether Hp persisted or not in the gastric flora. The LEfSe analysis of the FE and $P$ groups did not show any positive findings in bacterial flora. Figures $1 \mathrm{~B}$ and $2 \mathrm{D}$, and $4 \mathrm{~A}$ also indicated that there were no differences in gastric bacterial flora when Hp persisted. Furthermore, in these figures, the flora of the SE group was similar to that of the $\mathrm{N}$ group. Overall, these results indicated that after eliminating $\mathrm{Hp}$, the gastric bacterial flora could be partially restored. Lower relative abundance and richness, as mentioned in group SE, and reduced taxa implied that recovery might have some limits. No positive indicators were observed between group FE and group P, thus suggesting that the eradication treatment itself has little effect on the gastric flora.

\section{The different mucosal states are related to dysbacteriosis}

In order to further explore the differences between CG and AG, we next analyzed the four subgroups (N-CG, N-AG, SE-CG, and SE-AG). We found that N-CG had greater richness and diversity than the other three subgroups (except for Simpson's index comparing N-CG and SE-CG, $P=0.06$ ), and there were no differences between the three subgroups (Fig. 1C). The sum of the relative abundance of Firmicutes and Proteobacteria exceeded $50 \%$ in each subgroup. In group $\mathrm{N}$, gastric mucosal atrophy showed an increase in Firmicutes $(\mathrm{P}<0.001$, Fig. 4B) and was accompanied by a relative decrease in Proteobacteria (without statistical significance, Fig. 4B). PCoA showed that the bacterial structure was similar in all subgroups (N-CG, N-AG, SE-CG, and SE-AG, ANOSIM $R=-0.0659, P=0.963$, Fig. $2 E$ ). The same trend was not observed in group $\mathrm{SE}(\mathrm{P}=0.528, \mathrm{P}=0.430$,
Fig. 4B). Elevated levels of Firmicutes taxa: genera unclassified Lachnospiraceae and Romboutsia were detected in SE-CG samples, whereas Proteobacteria and Acidobacteria taxa were depleted in these samples (Fig. 5B). Compared to N-AG, SE-AG mainly manifested as fewer Firmicutes, including genera Ruminococcus gnavus group, unclassified Lachnospiraceae, and Ruminococcus 2 (Fig. 5C). Overall, gastric microbial communities were different at high taxonomic levels (e.g., genus and species compared with phylum and taxa) when comparing chronic gastritis and atrophic gastritis separately after successful eradication, indicating that the corresponding changes occurred at lower taxonomic levels (e.g., phylum and taxa compared with genus and species) as well.

\section{Analysis of functional changes in the gastric microbiome}

In order to infer the metagenome functional content, we used the PICRUSt2 tool based on the microbial community profiles obtained from the $16 \mathrm{~S}$ rDNA gene sequences. Differences in putative microbiome functionality and bacterial genera between the CG and AG groups were identified using the LEfSe approach $(\mathrm{LDA}>3)$. In group N, 11 identified KEGG functions were different between N-CG and N-AG (Fig. 6A), whereas no differential KEGG functions were found in subgroups (SE-CG and SE-AG) of the SE group. The subgroup SE-CG in the SE group was compared with the SE-AG subgroup in the SE group. As the results showed, the pathway involved in metabolism was overexpressed while the pathway involved in cell motility was inhibited in N-AG and SE-CG relative to N-CG (Fig. 6B). Additionally, we used correlation heatmaps to investigate the association between differential genera and KEGG pathways. Genera unclassified Alphaproteobacteria was positively correlated with cell motility, while genera unclassified Lachnospiraceae was negatively correlated with cell motility (Fig. 6A, 


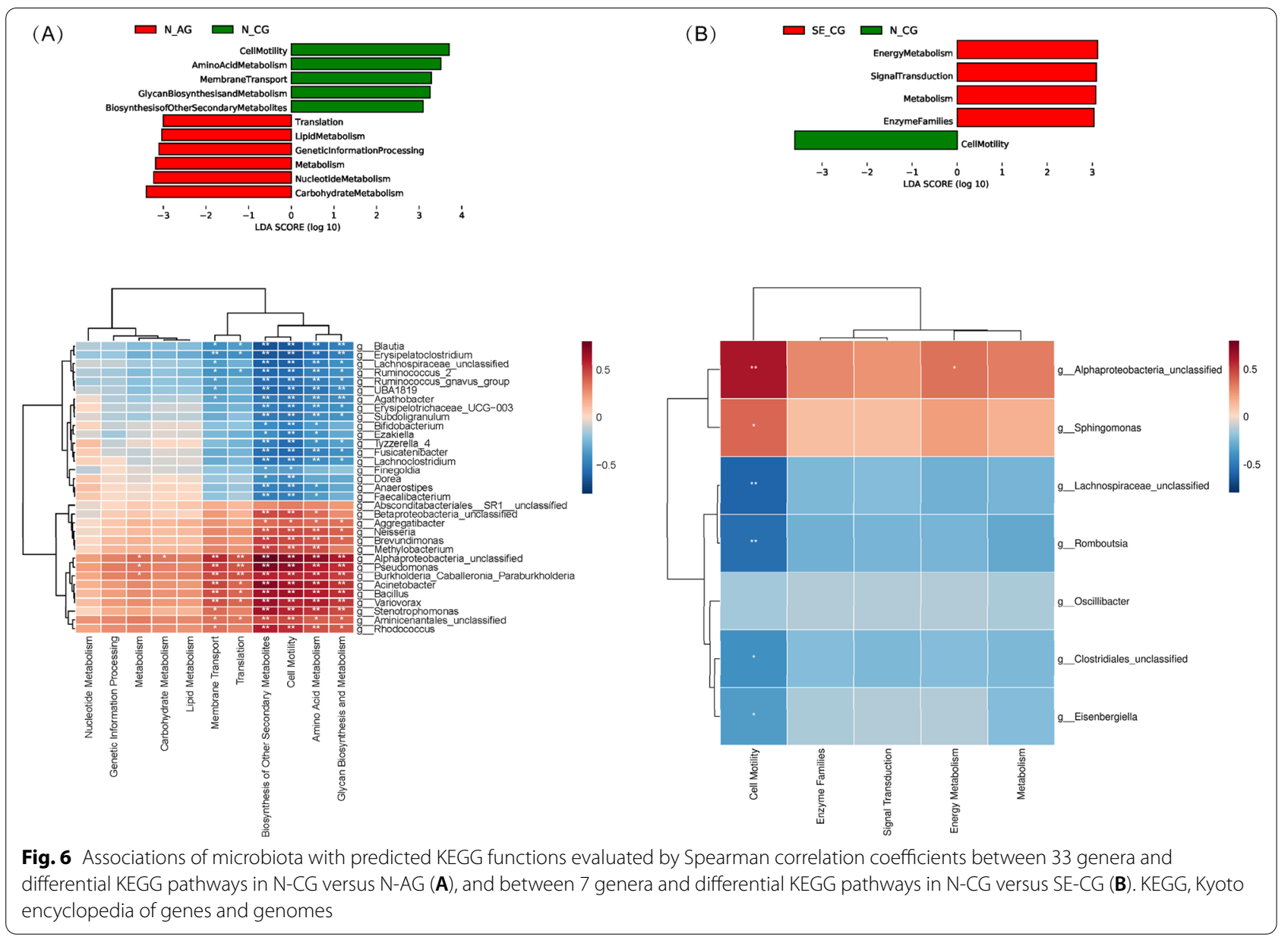

B). Interestingly, except for four genera (Bifidobacterium, Bacillus, unclassified Aminicenantales, and Rhodococcus), all negatively correlated genera are of the phylum Firmicutes, while all positively correlated genera are of the phylum Proteobacteria (Fig. 6A, B).

The pathological changes from chronic gastritis, precancerous lesions to gastric cancer represent a long process. Other non-Hp bacteria with specific functions are likely to be involved. The existing hypothesis is that nitrate-reducing bacterial species are associated with an increased risk of gastric carcinoma [26]. Eradication might have a potential impact on this function by changing the flora in the stomach. Therefore, we evaluated four subgroups and compared the results. Pairwise comparisons revealed that all nitrate and nitrite reductase functions had no significant differences (Additional file 3: Figure S3), suggesting that these functions were still at low levels in both CG and AG stages relative to gastric cancer.

\section{Discussion}

In the present study, we identified differential bacterial taxa and metagenomic functions before and after successful Hp eradication. Based on our results, the bacterial composition between the paired gastric antrum and corpus was highly similar, supported by previous studies $[20,44,45]$.

In the 16S rDNA gene variable regions, V3-V4 shows the highest taxonomic coverage, diversity, reproducibility, and PCR-amplification efficiency [46], and the primer set was determined to have high efficiency [47, 48]. 16S full-length sequencing requires third-generation sequencing methods, and its price is relatively high. The NovaSeq is sufficient for most taxonomic applications [49]. Qubit was used to quantify the library, and the qualified library concentration had to be above $2 \mathrm{nM}$. Gradient dilution was required, and then the mixture was mixed in the corresponding proportion according to the required sequencing volume. After $\mathrm{NaOH}$ denaturation, 
the Reagent was NovaSeq 6000 SP Reagent Kit (500 cycles), with at least 50,000 tags per sample. The HiSeq platform enables PE250 sequencing, which can obtain the same length of reads as MiSeq, but the volume and quality of sequencing data are much higher than MiSeq. When using the PE250 sequencing mode, HiSeq generates 10 times more data than MiSeq, allowing thousands of samples to be tested simultaneously. Compared with the HiSeq platform, the NovaSeq platform has higher data volume output, faster sequencing speed, higher sequencing quality, and more comprehensive application scenarios. It is more suitable for microbiome experiments such as amplification sequencing and metagenomic sequencing with a large sample size and data volume [50, 51].

Hp has the greatest impact on gastric bacterial composition and diversity [20]. In this study, we found that the abundance and diversity of bacteria after Hp colonization were significantly lower than in non-infected individuals. In addition, regardless of $\mathrm{Hp}$ infection, Proteobacteria was reported as the dominant bacterial group in the stomach [20,52]. Still, as the latest research no longer classifies Hp within Proteobacteria, Epsilonbacteraeota has become the most common phylum in Hpinfected patients [42, 43]. Despite this, the identified genera Curvibacter and Acinetobacter associated with Hp infection still belong to Proteobacteria. Curvibacter, which is a common part of the oral microflora, is prevalent in patients with atherosclerotic plaques [53], but the role of Curvibacter in gastric lesions remains to be explored. Earlier studies reported that atrophic gastritis was accompanied by a reduction in Hp colonization $[38,54]$. Ofori-Darko et al. concluded that the OmpAlike protein from Acinetobacter spp. could stimulate gastrin and IL-8 cytokine production, which suggests they can cause gastritis or participate in the transformation towards atrophic gastritis [55]. Acinetobacter appeared to be enriched after Hp colonization (Fig. 3B compared to the relatively low level in the SE and $\mathrm{N}$ groups without $\mathrm{Hp}$ colonization), and thus might play an important role in Hp pathogenesis. The LEfSe analysis showed that Acinetobacter was enriched in N-CG group compared with N-AG group. As shown in Fig. 6A, cell motility, amino acid metabolism, glycan biosynthesis and metabolism, membrane transport and biosynthesis of other secondary metabolites were positively correlated with Acinetobacter in N-CG. In addition to Hp itself, Acinetobacter might also be involved in the development of atrophic gastritis. Therefore, it was reasonable to speculate that this non-Hp bacteria might not only participate in the development of atrophic gastritis when $\mathrm{Hp}$ is present but also play a role alone when $\mathrm{Hp}$ colonization is reduced or eradicated.
The richness, diversity, and structure of the bacterial communities in the FE and P samples were highly similar. The results showed that once Hp occupies the stomach, it is difficult to disturb the gastric flora. Hence, $\mathrm{Hp}$ in the FE group remained dominant even after the eradication treatment, and its flora composition did not change. In the case of failure of Hp eradication, the effect of eradication drugs on the gastric flora appears to be limited. After successful eradication of $\mathrm{Hp}$, the phylum and genus composition of the gastric flora could be restored to levels close to those of Hp-negative subjects, and the bacterial diversity index increased, which was consistent with previous reports $[20,35]$. Still, there was a significant difference between the SE and $\mathrm{N}$ groups, revealing an outcome of limited recovery. We assumed that these differences might be due to some irreversible changes after Hp colonization. In order to confirm this, we evaluated whether gastric mucosal atrophy could affect the intragastric flora through four subgroups (N-CG, N-AG, SE-CG, SE-AG). The results showed that the richness and diversity of Hp-negative CG patients were significantly higher than those of the other subgroups, and no significant differences were observed among them (N-AG, SE-CG, and SE-AG). As an initiating factor, $\mathrm{Hp}$ is crucial in the progression of gastric mucosa from chronic gastritis to atrophic gastritis or even gastric cancer [12, 26, 56]. Still, $\mathrm{Hp}$ might not be the only causative factor in the process. This further confirmed our hypothesis that regardless of the gastric mucosal atrophy development, the gastric flora of patients with successful eradication was closer to N-AG. Hp often spontaneously disappears in elderly patients because of the progression of atrophic gastritis [57], which was not examined in this study but will have to be studied in the future as it could support the role of non-Hp species in the development of gastric cancer. Thus, while Hp infection might initiate atrophic gastritis, it might not mediate the final transforming events [58]. In addition, other bacterial species might initiate these events [59]. The bacterial driver could explain it, i.e., the passenger model in which $\mathrm{Hp}$ initiates the long carcinogenic process but is not a persisting factor during the process [60]. Some irreversible changes may occur after Hp colonization. Moreover, the proportion of Proteobacteria and Firmicutes was similar in the SE-CG and SE-AG groups. Thus, we speculated that Hp colonization probably accelerates the changes in the flora of SE-CG patients to atrophied flora. From this perspective, patients with successful eradication still seem to be at a higher risk than the normal population.

Recent studies showed that in the gastric carcinoma microbiota, increased nitrate reductase and nitrite reductase functions were considered as drivers of cancer development $[37,39,61]$. In order to assess this risk, we next 
addressed the functional features of the microbiota. Still, our results did not reveal this trend in atrophy patients. We speculate that the risk of dysbacteriosis in this regard is relatively low due to the successful elimination of $\mathrm{Hp}$.

To sum up, this article focused on the impact of eradication on the flora and assessment of the recovery of patients with successful Hp eradication. Moreover, we described the effects of gastric mucosal atrophy on the changes in gastric microbiota. Our study verified that in the presence of $\mathrm{Hp}$, the gastric flora was quite stable and, therefore, difficult to alter by antibiotics and highly effective acid suppressants. $\mathrm{Hp}$ is the initiating factor and a key link in Correa's cascade [26]. Moreover, even when advanced precancerous lesions occur, the successful removal of $\mathrm{Hp}$ is of great importance, especially in East Asia [62]. Thus, it seems that the risk of gastric cancer in patients with successful eradication has been greatly reduced, which has been confirmed by large-scale clinical research [21]. Still, for those who already experienced precancerous lesions such as atrophy, the risk is higher than in the normal aging stomach [22]. Consistent with this, our study reported that people who successfully eradicated $\mathrm{Hp}$ were closer to those with $\mathrm{Hp}$-negative gastric mucosal atrophy, which represented a smaller bacterial community. Interestingly, this change might not have a profound impact. Still, a previous study showed that Peptostreptococcus, Streptococcus, Parvimonas, Prevotella, Rothia, and Granulicatella were associated with emergence and persistence of gastric atrophy and intestinal metaplasia 1 year after eradication [63]. Future studies should examine the microbiome over time, from before to after eradication and during follow-up, in relation to the development of lesions.

This study has a few limitations. First, this was a single-center cross-sectional study with a small sample size, especially considering those enrolled in groups $\mathrm{P}$ and FE. Still, in this study, we implemented strict screening criteria and excluded the samples with $<1 \%$ of $\mathrm{Hp}$ sequence to obtain higher representativeness. Secondly, we did not obtain mucosal samples from the same subjects before and after $\mathrm{Hp}$ eradication treatment to achieve self-control. Third, the bacterial community is continuous and dynamic, so it was impossible to determine the causal relationship between these changes and different states. In addition, this study did not use PCR quantification techniques to quantify individual bacteria in different samples; thus, the analysis could only be based on the relative abundance of different bacteria. Finally, regarding causality, this study had a cross-sectional design, and causality could not be determined. It was added as a limitation. Therefore, further studies are still needed to verify and clarify the influence of eradication and precancerous lesions on gastric microbiome.

\section{Conclusions}

After $\mathrm{Hp}$ infection, the diversity and relative abundance of gastric microflora were significantly decreased. Yet, gastric microbiota could be partially restored to the Hp-negative status after successful eradication. Still, this effect was incomplete and might contribute to the long-term risks. The specific mechanisms and pathways underlying these changes will be explored in future research.

\section{Supplementary Information}

The online version contains supplementary material available at https://doi. org/10.1186/s13099-021-00460-2.

Additional file 1: Table S1. The examination results of each patient. Additional file 2: Table S2. The LEfSe analysis of the FE and P groups. Additional file 3: Figure S1. The histograms for the top10 bacterium in different taxa. Figure S2. Associations of biomarkers with inferred functions. Figure $\mathbf{S 3}$. Prediction of nitrate reductase and nitrite reductase functions.

\section{Acknowledgements}

We appreciate Yuan Shi (The First Affiliated Hospital of Zhejiang Chinese Medical University, Hangzhou, China) for helping us collect samples.

\section{Authors' contributions}

$\mathrm{BL}$ and LQM conceived and designed the study project. LQM, YLZ, SSW, and LC did experiments and performed analysis. LQM and YLZ wrote the manuscript. All authors contributed at all stages and critically reviewed the content. All authors read and approved the final manuscript.

\section{Funding}

This study was supported by Grants from the National Natural Science Foundation of China (No. 81770535).

Availability of data and materials

Data are available upon reasonable request from the authors.

\section{Declarations}

\section{Ethics approval and consent to participate}

The research protocol was approved by the Ethics Committee of The First Affiliated Hospital of Zhejiang Chinese Medical University. All studies were conducted in accordance with relevant guidelines and regulations. Ethics number: 2020-KL-107-02.

\section{Consent for publication}

Not applicable.

\section{Competing interests}

The authors declare that they have no competing interests.

\section{Author details}

${ }^{1}$ Department of Gastroenterology, The First Affiliated Hospital of Zhejiang Chinese Medical University, Hangzhou, China. ${ }^{2}$ Department of Gastroenterology, The First People's Hospital of Huzhou, The First Affiliated Hospital of Huzhou Teachers College, Huzhou, China. ${ }^{3}$ Department of Gastroenterology, Taizhou Hospital of Zhejiang Province affiliated to Wenzhou Medical University, Taizhou, China. ${ }^{4}$ Department of Gastroenterology, Guangxing Hospital Affiliated to Zhejiang Chinese Medical University, Hangzhou, China.

Received: 24 April 2021 Accepted: 7 October 2021

Published online: 13 October 2021 


\section{References}

1. Belkaid $Y$, Hand TW. Role of the microbiota in immunity and inflammation. Cell. 2014;157(1):121-41. https://doi.org/10.1016/j.cell.2014.03.011.

2. Oliphant K, Allen-Vercoe E. Macronutrient metabolism by the human gut microbiome: major fermentation by-products and their impact on host health. Microbiome. 2019;7(1):91. https://doi.org/10.1186/ s40168-019-0704-8.

3. Garza-Gonzalez E, Perez-Perez Gl, Maldonado-Garza HJ, Bosques-Padilla FJ. A review of Helicobacter pylori diagnosis, treatment, and methods to detect eradication. World J Gastroenterol. 2014;20(6):1438-49. https://doi. org/10.3748/wjg.v20.16.1438.

4. Guevara B, Cogdill AG. Helicobacter pylori: a review of current diagnostic and management strategies. Dig Dis Sci. 2020;65(7):1917-31. https://doi. org/10.1007/s10620-020-06193-7.

5. Chey WD, Leontiadis Gl, Howden CW, Moss SF. ACG clinical guideline: treatment of Helicobacter pylori infection. Am J Gastroenterol. 2017;112(2):212-39. https://doi.org/10.1038/ajg.2016.563.

6. McColl KE. Clinical practice. Helicobacter pylori infection. N Engl J Med. 2010;362(17):1597-604. https://doi.org/10.1056/NEJMcp1001110.

7. Parikh NS, Ahlawat R. Helicobacter pylori. Treasure Island: StatPearls; 2021.

8. Zamani M, Ebrahimtabar F, Zamani V, Miller WH, Alizadeh-Navaei R, Shokri-Shirvani J, et al. Systematic review with meta-analysis: the worldwide prevalence of Helicobacter pylori infection. Aliment Pharmacol Ther. 2018:47(7):868-76. https://doi.org/10.1111/apt.14561.

9. Hooi JKY, Lai WY, Ng WK, Suen MMY, Underwood FE, Tanyingoh D, et al. Global prevalence of Helicobacter pylori infection: systematic review and meta-analysis. Gastroenterology. 2017;153(2):420-9. https://doi.org/10. 1053/j.gastro.2017.04.022

10. Shi R, Xu S, Zhang H, Ding Y, Sun G, Huang X, et al. Prevalence and risk factors for Helicobacter pylori infection in Chinese populations. Helicobacter. 2008;13(2):157-65. https://doi.org/10.1111/j.1523-5378.2008.00586.x.

11. Wang W, Jiang W, Zhu S, Sun X, Li P, Liu K, et al. Assessment of prevalence and risk factors of Helicobacter pylori infection in an oilfield Community in Hebei, China. BMC Gastroenterol. 2019;19(1):186. https://doi.org/10.1186/ s12876-019-1108-8

12. Ishaq S, Nunn L. Helicobacter pylori and gastric cancer: a state of the art review. Gastroenterol Hepatol Bed Bench. 2015;8(Suppl 1):6-14.

13. Diaz P, Valenzuela Valderrama M, Bravo J, Quest AFG. Helicobacter pylori and gastric cancer: adaptive cellular mechanisms involved in disease progression. Front Microbiol. 2018;9:5. https://doi.org/10.3389/fmicb. 2018.00005.

14. Lee YC, Chiang TH, Chou CK, Tu YK, Liao WC, Wu MS, et al. Association between Helicobacter pylori eradication and gastric cancer incidence: a systematic review and meta-analysis. Gastroenterology. 2016;150(5):1113-24. https://doi.org/10.1053/j.gastro.2016.01.028

15. Leung WK, Wong IOL, Cheung KS, Yeung KF, Chan EW, Wong AYS, et al. Effects of Helicobacter pylori treatment on incidence of gastric cancer in older individuals. Gastroenterology. 2018;155(1):67-75. https://doi.org/10. 1053/j.gastro.2018.03.028.

16. Kumar S, Metz DC, Ellenberg S, Kaplan DE, Goldberg DS. Risk factors and incidence of gastric cancer after detection of Helicobacter pylori infection: a large cohort study. Gastroenterology. 2020;158(3):527-36. https://doi. org/10.1053/j.gastro.2019.10.019.

17. Malfertheiner P, Megraud F, O'Morain CA, Gisbert JP, Kuipers EJ, Axon AT, et al. Management of Helicobacter pylori infection-the Maastricht V/Florence Consensus Report. Gut. 2017;66(1):6-30. https://doi.org/10.1136/ gutjnl-2016-312288.

18. Sugano K, Tack J, Kuipers EJ, Graham DY, El-Omar EM, Miura S, et al. Kyoto global consensus report on Helicobacter pylori gastritis. Gut. 2015;64(9):1353-67. https://doi.org/10.1136/gutjnl-2015-309252.

19. Li L, Zhou X, Xiao S, Ye F, Zhang G. The effect of Helicobacter pylori eradication on the gastrointestinal microbiota in patients with duodenal ulcer. J Gastrointest Liver Dis. 2016;25(2):139-46. https://doi.org/10.15403/jgld. 2014.1121.252.hpe.

20. LiTH, Qin Y, Sham PC, Lau KS, Chu KM, Leung WK. Alterations in gastric microbiota after H. pylori eradication and in different histological stages of gastric carcinogenesis. Sci Rep. 2017;7:44935. https://doi.org/10.1038/ srep44935.

21. Mera RM, Bravo LE, Camargo MC, Bravo JC, Delgado AG, Romero-Gallo $J$, et al. Dynamics of Helicobacter pylori infection as a determinant of progression of gastric precancerous lesions: 16-year follow-up of an eradication trial. Gut. 2018;67(7):1239-46. https://doi.org/10.1136/ gutjnl-2016-311685.

22. Wong BC, Lam SK, Wong WM, Chen JS, Zheng TT, Feng RE, et al. Helicobacter pylori eradication to prevent gastric cancer in a high-risk region of China: a randomized controlled trial. Jama. 2004;291(2):187-94. https:// doi.org/10.1001/jama.291.2.187

23. Rolig AS, Cech C, Ahler E, Carter JE, Ottemann KM. The degree of Helicobacter pylori-triggered inflammation is manipulated by preinfection host microbiota. Infect Immun. 2013;81(5):1382-9. https://doi.org/10.1128/iai. 00044-13.

24. Bruno G, Zaccari P, Rocco G, Scalese G, Panetta C, Porowska B, et al. Proton pump inhibitors and dysbiosis: current knowledge and aspects to be clarified. World J Gastroenterol. 2019;25(22):2706-19. https://doi.org/10. 3748/wjg.v25.i22.2706

25. Paroni Sterbini F, Palladini A, Masucci L, Cannistraci CV, Pastorino R,

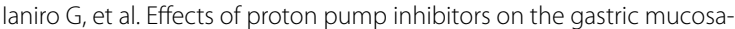
associated microbiota in dyspeptic patients. Appl Environ Microbiol. 2016:82(22):6633-44. https://doi.org/10.1128/AEM.01437-16.

26. Correa P. Human gastric carcinogenesis: a multistep and multifactorial process--First American Cancer Society Award Lecture on Cancer Epidemiology and Prevention. Cancer Res. 1992;52(24):6735-40.

27. Liou JM, Chen CC, Chang CM, Fang YJ, Bair MJ, Chen PY, et al. Longterm changes of gut microbiota, antibiotic resistance, and metabolic parameters after Helicobacter pylori eradication: a multicentre, open-label, randomised trial. Lancet Infect Dis. 2019;19(10):1109-20. https://doi.org/ 10.1016/S1473-3099(19)30272-5.

28. Abreu MT, Peek RM, Jr. Gastrointestinal malignancy and the microbiome. Gastroenterology. 2014;146(6):1534-46. https://doi.org/10.1053/j.gastro. 2014.01.001.

29. Nardone G, Compare D. The human gastric microbiota: Is it time to rethink the pathogenesis of stomach diseases? United European Gastroenterol J. 2015;3(3):255-60. https://doi.org/10.1177/2050640614566846.

30. Ohno H, Satoh-Takayama N. Stomach microbiota, Helicobacter pylori, and group 2 innate lymphoid cells. Exp Mol Med. 2020;52(9):1377-82. https:// doi.org/10.1038/s12276-020-00485-8.

31. Hunt $\mathrm{RH}$, Camilleri M, Crowe SE, El-Omar EM, Fox JG, Kuipers EJ, et al. The stomach in health and disease. Gut. 2015;64(10):1650-68. https://doi.org/ 10.1136/gutjnl-2014-307595.

32. Lofgren JL, Whary MT, Ge Z, Muthupalani S, Taylor NS, Mobley M, et al. Lack of commensal flora in Helicobacter pylori-infected INS-GAS mice reduces gastritis and delays intraepithelial neoplasia. Gastroenterology. 2011;140(1):210-20. https://doi.org/10.1053/j.gastro.2010.09.048.

33. Lertpiriyapong K, Whary MT, Muthupalani S, Lofgren JL, Gamazon $E R$, Feng $Y$, et al. Gastric colonisation with a restricted commensal microbiota replicates the promotion of neoplastic lesions by diverse intestinal microbiota in the Helicobacter pylori INS-GAS mouse model of gastric carcinogenesis. Gut. 2014;63(1):54-63. https://doi.org/10.1136/ gutjnl-2013-305178.

34. Liu X, Shao L, Liu X, Ji F, Mei Y, Cheng Y, et al. Alterations of gastric mucosal microbiota across different stomach microhabitats in a cohort of 276 patients with gastric cancer. EBioMedicine. 2019;40:336-48. https://doi. org/10.1016/j.ebiom.2018.12.034.

35. Park $C H$, Lee $A R$, Lee $Y R$, Eun CS, Lee SK, Han DS. Evaluation of gastric microbiome and metagenomic function in patients with intestinal metaplasia using 16S rRNA gene sequencing. Helicobacter. 2019;24(1):e12547. https://doi.org/10.1111/hel.12547.

36. Coker OO, Dai Z, Nie Y, Zhao G, Cao L, Nakatsu G, et al. Mucosal microbiome dysbiosis in gastric carcinogenesis. Gut. 2018;67(6):1024-32. https:// doi.org/10.1136/gutjnl-2017-314281.

37. Ferreira RM, Pereira-Marques J, Pinto-Ribeiro I, Costa JL, Carneiro F, Machado JC, et al. Gastric microbial community profiling reveals a dysbiotic cancer-associated microbiota. Gut. 2018;67(2):226-36. https://doi. org/10.1136/gutjnl-2017-314205.

38. Farinati F, Valiante F, Germanà B, Della Libera G, Baffa R, Rugge M, et al Prevalence of Helicobacter pylori infection in patients with precancerous changes and gastric cancer. Eur J Cancer Prevent. 1993;2(4):321-6. https://doi.org/10.1097/00008469-199307000-00006.

39. Wu ZF, Zou K, Wu GN, Jin ZJ, Xiang CJ, Xu S, et al. A comparison of tumorassociated and non-tumor-associated gastric microbiota in gastric cancer patients. Dig Dis Sci. 2020. https://doi.org/10.1007/s10620-020-06415-y. 
40. Park CH, Lee JG, Lee AR, Eun CS, Han DS. Network construction of gastric microbiome and organization of microbial modules associated with gastric carcinogenesis. Sci Rep. 2019;9(1):12444. https://doi.org/10.1038/ s41598-019-48925-4.

41. Kim J, Kim N, Jo HJ, Park JH, Nam RH, Seok YJ, et al. An appropriate cutoff value for determining the colonization of Helicobacter pylori by the pyrosequencing method: comparison with conventional methods. Helicobacter. 2015;20(5):370-80. https://doi.org/10.1111/hel.12214.

42. Waite DW, Vanwonterghem I, Rinke C, Parks DH, Zhang Y, Takai K, et al. Erratum: Addendum: comparative genomic analysis of the Class Epsilonproteobacteria and proposed reclassification to Epsilonbacteraeota (phyl. nov.). Front Microbiol. 2018;9:772. https://doi.org/10.3389/fmicb.2018. 00772.

43. Waite DW, Vanwonterghem I, Rinke C, Parks DH, Zhang Y, Takai K, et al. Comparative genomic analysis of the class Epsilonproteobacteria and proposed reclassification to Epsilonbacteraeota (phyl. nov.). Front Microbiol. 2017;8:682. https://doi.org/10.3389/fmicb.2017.00682.

44. Li XX, Wong GL, To KF, Wong VW, Lai LH, Chow DK, et al. Bacterial microbiota profiling in gastritis without Helicobacter pylori infection or non-steroidal anti-inflammatory drug use. PLOS ONE. 2009;4(11):e7985. https://doi.org/10.1371/journal.pone.0007985.

45. Bik EM, Eckburg PB, Gill SR, Nelson KE, Purdom EA, Francois F, et al. Molecular analysis of the bacterial microbiota in the human stomach. Proc Natl Acad Sci USA. 2006;103(3):732-7. https://doi.org/10.1073/pnas. 0506655103.

46. Thijs S, Op De Beeck M, Beckers B, Truyens S, Stevens V, Van Hamme JD, et al. Comparative evaluation of four bacteria-specific primer pairs for $16 \mathrm{~S}$ rRNA gene surveys. Front Microbiol. 2017;8:494. https://doi.org/10.3389/ fmicb.2017.00494

47. Roos S, Dicksved J, Tarasco V, Locatelli E, Ricceri F, Grandin U, et al. 454 pyrosequencing analysis on faecal samples from a randomized DBPC trial of colicky infants treated with Lactobacillus reuteri DSM 17938. PLoS ONE. 2013;8(2):e56710. https://doi.org/10.1371/journal.pone.0056710.

48. Logue JB, Stedmon CA, Kellerman AM, Nielsen NJ, Andersson AF, Laudon $H$, et al. Experimental insights into the importance of aquatic bacterial community composition to the degradation of dissolved organic matter. ISME J. 2016;10(3):533-45. https://doi.org/10.1038/ismej.2015.131.

49. Knight R, Vrbanac A, Taylor BC, Aksenov A, Callewaert C, Debelius J, et al. Best practices for analysing microbiomes. Nat Rev Microbiol. 2018;16(7):410-22. https://doi.org/10.1038/s41579-018-0029-9.

50. Sun HZ, Xue M, Guan LL, Liu J. A collection of rumen bacteriome data from 334 mid-lactation dairy cows. Scientific data. 2019;6:180301. https:// doi.org/10.1038/sdata.2018.301.

51. de Muinck EJ, Trosvik P, Gilfillan GD, Hov JR, Sundaram AYM. A novel ultra high-throughput 16S rRNA gene amplicon sequencing library preparation method for the Illumina HiSeq platform. Microbiome. 2017;5(1):68. https://doi.org/10.1186/s40168-017-0279-1.

52. Jo HJ, Kim J, Kim N, Park JH, Nam RH, Seok YJ, et al. Analysis of gastric microbiota by pyrosequencing: minor role of bacteria other than Helicobacter pylori in the gastric carcinogenesis. Helicobacter. 2016;21(5):364-74. https://doi.org/10.1111/hel.12293.

53. Ziganshina EE, Sharifullina DM, Lozhkin AP, Khayrullin RN, Ignatyev IM Ziganshin AM. Bacterial communities associated with atherosclerotic plaques from Russian individuals with atherosclerosis. PLoS ONE. 2016;11(10):e0164836. https://doi.org/10.1371/journal.pone.0164836.

54. Kuipers EJ. Review article: exploring the link between Helicobacter pylori and gastric cancer. Aliment Pharmacol Ther. 1999;13(Suppl 1):3-11. https://doi.org/10.1046/j.1365-2036.1999.00002.x.

55. Ofori-Darko E, Zavros Y, Rieder G, Tarlé SA, Van Antwerp M, Merchant JL. An OmpA-like protein from Acinetobacter spp. stimulates gastrin and interleukin-8 promoters. Infect Immun. 2000;68(6):3657-66. https://doi. org/10.1128/iai.68.6.3657-3666.2000.

56. Hatakeyama M. Helicobacter pylori CagA and gastric cancer: a paradigm for hit-and-run carcinogenesis. Cell Host Microbe. 2014;15(3):306-16. https://doi.org/10.1016/j.chom.2014.02.008.

57. Chen S, Ying L, Kong M, Zhang Y, Li Y. The prevalence of Helicobacter pylori infection decreases with older age in atrophic gastritis. Gastroenterol Res Pract. 2013;2013:494783. https://doi.org/10.1155/2013/494783.

58. Watari J, Chen N, Amenta PS, Fukui H, Oshima T, Tomita T, et al. Helicobacter pylori associated chronic gastritis, clinical syndromes, precancerous lesions, and pathogenesis of gastric cancer development. World J Gastroenterol. 2014;20(18):5461-73. https://doi.org/10.3748/wjg.v20.i18. 5461.

59. Sarhadi V, Mathew B, Kokkola A, Karla T, Tikkanen M, Rautelin H, et al. Gut microbiota of patients with different subtypes of gastric cancer and gastrointestinal stromal tumors. Gut Pathog. 2021;13(1):11. https://doi. org/10.1186/s13099-021-00403-x.

60. Tjalsma H, Boleij A, Marchesi JR, Dutilh BE. A bacterial driver-passenger model for colorectal cancer: beyond the usual suspects. Nat Rev Microbiol. 2012;10(8):575-82. https://doi.org/10.1038/nrmicro2819.

61. Chen XH, Wang A, Chu AN, Gong YH, Yuan Y. Mucosa-associated microbiota in gastric cancer tissues compared with non-cancer tissues. Front Microbiol. 2019;10:1261. https://doi.org/10.3389/fmicb.2019.01261.

62. Li WQ, Ma JL, Zhang L, Brown LM, Li JY, Shen L, et al. Effects of Helicobacter pylori treatment on gastric cancer incidence and mortality in subgroups. J Natl Cancer Inst. 2014. https://doi.org/10.1093/jnci/dju1 16.

63. Sung JJY, Coker OO, Chu E, Szeto CH, Luk STY, Lau HCH, et al. Gastric microbes associated with gastric inflammation, atrophy and intestinal metaplasia 1 year after Helicobacter pylori eradication. Gut. 2020;69(9):1572-80. https://doi.org/10.1136/gutjnl-2019-319826.

\section{Publisher's Note}

Springer Nature remains neutral with regard to jurisdictional claims in published maps and institutional affiliations.

\footnotetext{
Ready to submit your research? Choose BMC and benefit from:

- fast, convenient online submission

- thorough peer review by experienced researchers in your field

- rapid publication on acceptance

- support for research data, including large and complex data types

- gold Open Access which fosters wider collaboration and increased citations

- maximum visibility for your research: over 100M website views per year
}

At $\mathrm{BMC}$, research is always in progress.

Learn more biomedcentral.com/submissions 